
A. L. O. (2021). Valores Pessoais no Consumo de Cafés em Cápsula. Consumer Behavior Review, 5(2), 288-306.

ISSN: 2526-7884

Editor: Prof. Dr. Marconi Freitas da Costa E-mail: cbr@ufpe.br
Avaliação: Double blind review

Recebido: 10 de Janeiro, 2021

Aceito: 14 de Abril, 2021

\title{
VALORES PESSOAIS NO CONSUMO DE CAFÉS EM CÁPSULA
}

\section{Personal Values in Coffee Consumption in Capsule}

\author{
Alberdan José da Silva Teodoro ${ }^{1}$ \\ ORCID: http://orcid.org/0000-0002-9315-218X \\ E-mail: alberdan.teodoro@estudante.ufla.br \\ Marcos Giovane da Silva ${ }^{1}$ \\ ORCID: http://orcid.org/0000-0001-8410-6053 \\ E-mail: marcosufsj21@gmail.com \\ Luiz Henrique de Barros Vilas Boas ${ }^{1}$ \\ ORCID: http://orcid.org/0000-0002-6429-1420 \\ E-mail: luiz.vilasboas@ufla.br \\ Álvaro Leonel de Oliveira Castro ${ }^{1}$ \\ ORCID: http://orcid.org/0000-0002-2779-6745 \\ E-mail: alvaroleonel@outlook.com
}

${ }^{1}$ Universidade Federal de Lavras, Lavras, Minas Gerais, Brasil

\begin{abstract}
Resumo
A pesquisa buscou identificar os valores pessoais que orientam o comportamento dos consumidores de cafés em cápsulas, e discutilos sob às perspectivas da teoria de valores pessoais. Trata-se de uma pesquisa qualitativa, descritiva, a qual utilizou-se das técnicas projetivas, conclusão de frase e foto-elicitação, em conjunto à técnica de entrevista em profundidade Laddering. Para análise dos dados e resultados, foi utilizado o software LadderUX. Os resultados identificaram os
\end{abstract}

\begin{abstract}
The research sought to identify the personal values that guide the behavior of coffee consumers in capsules, and to discuss them from the perspective of the theory of personal values. It is a qualitative, descriptive research, which used projective techniques, sentence completion and photo-elicitation, together with the laddering in-depth interview technique. LadderUX software was used to analyze the data and results. The results identified the values: benevolence of care,
\end{abstract}


valores: benevolência de cuidado, autodireção por ação, realização, segurança pessoal e hedonismo; como relevantes diante do consumo de café em cápsulas. Ademais, o uso das técnicas projetivas e a Laddering foram eficazes para identificar os atributos considerados positivos pelos consumidores. A contribuição teórica se refere a combinação entre as teorias cadeia meios-fim e valores pessoais. Metodologicamente, a contribuição se refere a combinação entre as técnicas projetivas e a técnica Laddering. Quanto as implicações gerenciais, o estudo fornece orientações para a construção de estratégias de marketing para a comercialização do produto. E, socialmente, identificou-se a busca dos consumidores em atender estágios finais de existência por meio do consumo, por consequência, os relacionamentos com a marca a fim de usufruir e atender seus valores e crenças.

Palavras-chave: Valores pessoais; Projetivas; Laddering; Consumo; Café. self-direction by action, achievement, personal security and hedonism; relevant to the consumption of coffee in capsules. In addition, the use of projective techniques and Laddering were effective in identifying the attributes considered positive by consumers. The theoretical contribution refers to the combination of the means-end chain theories and personal values. Methodologically, the contribution refers to the combination of projective techniques and the Laddering technique. As for managerial implications, the study provides guidance for building marketing strategies for product marketing. And, socially, the search for consumers to attend final stages of existence through consumption was identified, consequently, the relationships with the brand in order to enjoy and meet its values and beliefs.

Keywords: Personal values; Projective; Laddering; Consumption. Coffee.

This work is licensed under a Creative Commons Attribution 4.0 International License.

\section{INTRODUÇÃO}

Na dinâmica de mercado e nos processos de globalização presentes no contexto da sociedade contemporânea, nota-se que alguns aspectos, tem modificado e influenciado as relações entre empresas e consumidores. A tecnologia está cada vez mais presente no cotidiano no indivíduo, visando facilitar suas atividades, rotinas e hábitos alimentares (Gandia et al., 2018). Deste modo, o produto cápsulas de café são uma consequência das mudanças da sociedade e do intenso dinamismo presente nesse contexto. Segundo dados da pesquisa realizada pela Euromonitor Consulting, encomendadas pela ABIC $(2015 ; 2017)$ o consumo brasileiro de cafés em cápsulas cresceu cerca de $21 \%$ entre 2014 e 2019, e tinha-se uma projeção de crescimento de 9\% entre os anos de 2017 a 2021.

Além disso, percebe-se no cenário mercadológico que, apenas vender um produto ou serviço já não é mais suficiente, torna-se necessário convencer o cliente, torná-lo um consumidor frequente e fiel. Ou seja, torna-se necessário, idealizar conceitos e gerar valor. Logo, estudos realizados anteriormente, e assim como este, propuseram um objetivo: entender o consumidor em níveis cognitivos ainda mais elevados, que podem atingir os valores pessoais do indivíduo (Vilas Boas, 2005; Castro et al., 2018).

Alguns autores relatam em seus estudos, o desenvolvimento e a dinâmica dos fatores e estímulos que podem influenciar o comportamento do consumidor perante sua decisão de compra e consumo, sendo eles: os sentidos humanos, a percepção, necessidades e motivações, circunstâncias, ambiente da loja, etc. (Krishna, 2012; Solomon, 2016). Tais questões, dizem muito a respeito das razões do comportamento de consumo e ainda são um mistério, "uma caixa preta a ser aberta" por acadêmicos da neurociência e demais cientistas nas áreas de ciências sociais (Almeida et al., 2015, p. 97). Por outro lado, Solomon (2016) é mais enfático e relata que estudar o comportamento de consumo é compreender os processos e as atividades, no qual os indivíduos e/ou grupos se envolvem quando compram e consomem determinados produtos, serviços e marcas.

Uma forma de compreender os fatores que motivam a decisão de compra, e as relações cognitivas do indivíduo frente ao consumo de produtos e serviços ofertados pelas indústrias, é 
utilizando a teoria de valores pessoais (Schwartz, 1992; 2017; Schwartz et al., 2012) em conjunto com a perspectiva teórica da cadeia meios-fim (Gutman, 1982). Estas teorias, quando aplicadas a estudos sobre o comportamento do consumidor, buscam entender como as motivações estão relacionadas à julgamentos, critérios de seleção, e justificação de ações de indivíduos mediante ao consumo. Percebese que a teoria de valores de valores pessoais (Schwartz, 2017) pode contribuir para a compreensão das expectativas, percepções e o grau de importância, onde o sujeito percebe e atribui tais relações ao consumo de um produto, serviço ou marca, tornando-se propício conhecer suas motivações e comportamentos. Logo, estudos apontam que os valores pessoais podem agir como motivadores de consumo, principalmente na área de alimentos (Gandia et al., 2018; Castro et al., 2019; Brümmer \& Zander, 2020).

Isso posto, este estudo possui como objetivo, identificar como os valores pessoais sustentam a estrutura cognitiva referente ao consumo dos cafés em cápsulas disponíveis no mercado, e discuti-los frente às perspectivas das teorias de valores pessoais (Schwartz, 2017) e da cadeia meios-fim (Gutman, 1982). Aproveitando as sugestões de estudos futuros de Gandia et al. (2018), Castro et al. (2019) e Samoggia e Riedel (2018). Neste sentido, o presente estudo torna-se relevante para o âmbito acadêmico, pois correlaciona duas teorias sobre o comportamento do consumidor. E no campo gerencial poderá gerar novos insights quanto aos critérios que envolvem a compra e consumo de cafés em cápsulas, podendo atingir marcas tradicionais como Nespresso®, Dolce Gusto®, Três Corações $®$, mas também os pequenos produtores que comercializam cafés diferenciados através de cápsulas em lotes exclusivos.

\section{REFERENCIAL TEÓRICO Valores pessoais}

Os estudos sobre valores humanos possuem abordagens em diversas áreas do conhecimento, onde cada uma examina o seu ponto de vista, expondo suas explicações teóricas e práticas. Rokeach em 1968, foi um dos primeiros autores a abordar o tema enquanto elemento motivacional do indivíduo. Segundo o autor, os valores são considerados crenças duradouras que agem como padrões de conduta individual ou coletivo, na busca dos objetivos e metas a serem atingidos durante a vida do indivíduo. Os valores também podem interferir nas atitudes do comportamento social, sendo elas de forma consciente ou inconsciente, e são considerados de caráter terminal, onde representam os objetivos perseguidos pelo indivíduo, ou instrumental, sendo caracterizados pelas atitudes praticadas pelo indivíduo em seu cotidiano, e que orientam a busca das metas e objetivos (Rokeach, 1973; 1989).

Os valores pessoais se modificam em função das mudanças ocorridas na sociedade, em termos culturais, políticos, tecnológicos e sociais, e que podem influenciar comportamentos individuais e coletivos (Kahle et al., 1988). Nas áreas das ciências sociais, como, sociologia, antropologia, filosofia e psicologia, os valores humanos são estudados na tentativa de caracterizar indivíduos, e por consequência as sociedades e suas metamorfoses ao decorrer do tempo (Eccles \& Wigfield, 2002). Alguns autores ganharam destaque nesse campo de pesquisa, e continuam atualizando os estudos sobre valores humanos e suas relações sociais e individuais, é o caso do autor Shalom H. Schwartz.

Schwartz (1992) desenvolveu a Teoria dos Valores Básicos Humanos, diante de um estudo com participação de 20 países, classificados em 40 amostras, e se atentou a destacar as compatibilidades e os conflitos dos 10 valores humanos encontrados. 0 estudo também possui como peculiaridade a distinção entre àqueles valores que apresentam relações compatíveis e incompatíveis entre si. Inicialmente, o autor desenvolveu dez domínios de valores pessoais, organizados em uma faceta polar, formando um continuum motivacional. Esta teoria relata que os valores pessoais podem se apresentar de maneira sistematizada, em que durante a decorrência dos objetivos, alguns valores podem ser priorizados sobre outros e, assim, atender aos interesses do indivíduo. O que distingue um determinado valor de outro é o tipo de objetivo ou motivação envolvida em que o valor poderá se manifestar (Schwartz, 1992; 2017; Schwartz et al., 2012).

A partir de uma análise de escalonamento multidimensional, Schwartz et al., (2012) realizaram outra pesquisa, e para isso utilizaram 344 estudos realizados em 83 países, desta forma, a perspectiva teórica passou por uma reformulação. Assim, os dez valores identificados por Schwartz em 1992 
foram refinados, dando origem à mais nove novos valores, ficando 19 valores universais, que conseguem aumentar a capacidade explicativa e abranger novas perspectivas de análise da teoria (Schwartz, 2017).

Segundo Schwartz et al., (2012), os valores são caracterizados em duas dimensões. Por um lado, aqueles caracterizados pela autoproteção ou prevenção à ansiedade e a proteção do seu self, por outro lado, aqueles que visam o crescimento livre de ansiedade, relacionado ao autodesenvolvimento do sujeito. Além disso, os valores também são distinguidos de acordo com seus interesses, ora podendo se apresentar sob os aspectos voltados para resultados de foco pessoal/particular, ora sob foco social/coletivo.

Os dezenove valores presentes no círculo central (Figura 1), são categorizados em quatro quadrantes, denominados como valores de ordem superior, sendo ele: abertura a mudanças - o sujeito age em função de suas próprias prerrogativas tornando-se receptivo à novas situações; autoaprimoramento - o sujeito busca por melhorar seu status quo; conservadorismo - consiste na busca do sujeito por manter e/ou se sujeitar a situações visando preservar seu status quo; e, por fim, a autotranscedência - o sujeito visa interesses que estão além de si próprio, buscam por melhorias que ultrapassam a individualidade (Schwartz, 2017).

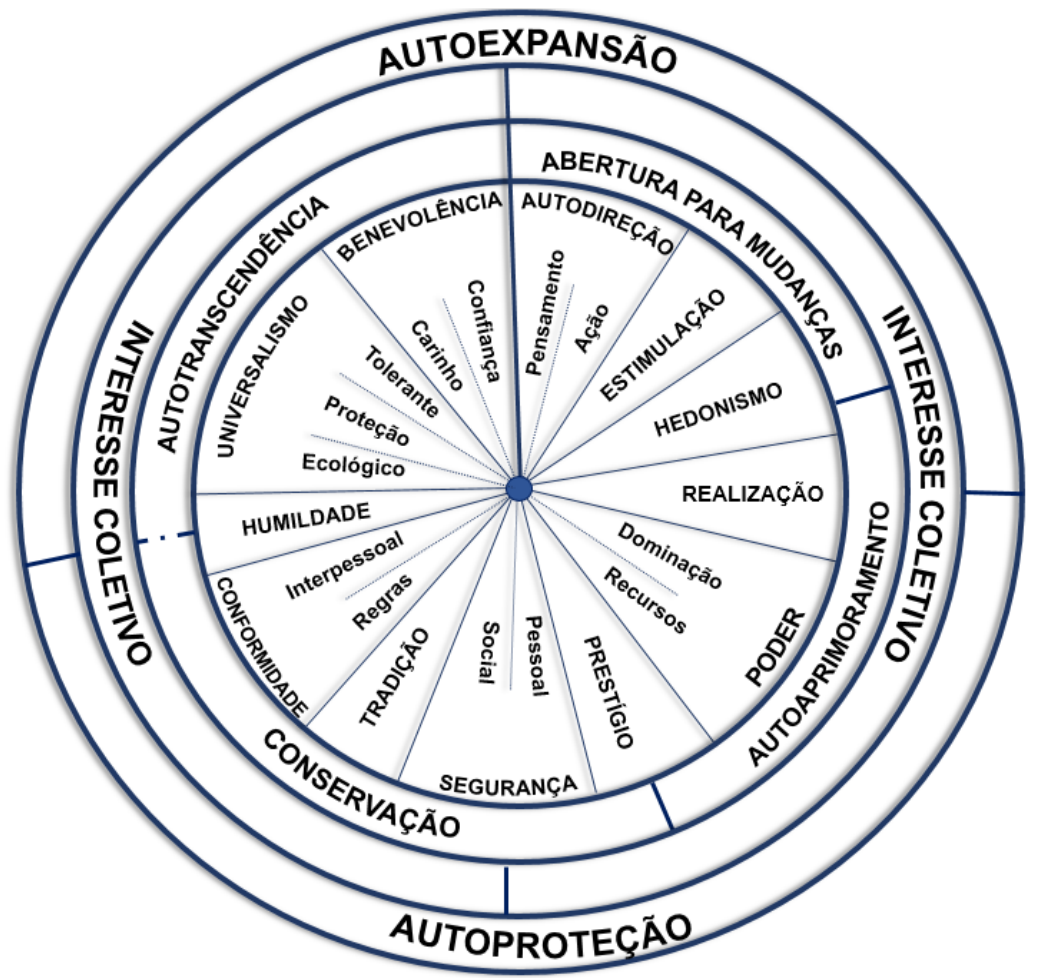

Fonte: Adaptado de Schwartz (2017).

Figura 1. Estrutura circular motivacional dos valores pessoais

Estudar determinados contextos, atitudes e motivações sob a ótica da versão refinada da teoria de valores resulta em maiores e melhores possibilidades de compreensão acerca dos processos cognitivos, bem como às experiências do indivíduo (Vilas Boas, 2005; Castro et al., 2019). Na área de marketing e comportamento de consumo, os pesquisadores podem entender as relações motivacionais diante dos valores pessoais (Ha \& Jang, 2013;). A Quadro 1 apresenta os dezenove valores da versão refinada, de 2017, da teoria localizados no interior da estrutura circular da teoria de valores: 


\begin{tabular}{|c|c|}
\hline Valor & Definições conceituais em termos de objetivos motivacionais \\
\hline Auto-direção - pensamento & Liberdade para cultivar as próprias ideias e habilidades \\
\hline Auto-direção - ação & Liberdade para determinar as próprias ações \\
\hline Estimulação & Excitação, novidade e mudança \\
\hline Hedonismo & Prazer e gratificação sensual \\
\hline Realização & Sucesso de acordo com os padrões sociais \\
\hline Poder - domínio & Poder exercendo controle sobre as pessoas \\
\hline Poder - recursos & Poder através do controle de recursos materiais e sociais \\
\hline Prestígio & Manter a imagem pública e evitar a humilhação \\
\hline Segurança - pessoal & Segurança no ambiente imediato \\
\hline Segurança - social & Segurança e estabilidade na sociedade em geral \\
\hline Tradição & Manter e preservar tradições culturais, familiares ou religiosas \\
\hline Conformidade - regras & Cumprimento de regras, leis e obrigações formais \\
\hline Conformidade interpessoal & Evitar perturbar ou prejudicar outras pessoas \\
\hline Humildade & $\begin{array}{l}\text { Reconhecendo a insignificância de alguém no esquema maior das } \\
\text { coisas }\end{array}$ \\
\hline Universalismo - natureza & Preservação do meio ambiente natural \\
\hline $\begin{array}{l}\text { Universalismo - } \\
\text { preocupação }\end{array}$ & $\begin{array}{l}\text { Compromisso com a igualdade, a justiça e a proteção de todas as } \\
\text { pessoas }\end{array}$ \\
\hline Universalismo - tolerância & Aceitação e compreensão daqueles que são diferentes a si mesmo \\
\hline Benevolência - cuidar & Devoção ao bem-estar dos membros do grupo \\
\hline $\begin{array}{l}\text { Benevolência - } \\
\text { confiabilidade }\end{array}$ & Ser um membro confiável e confiável do grupo \\
\hline
\end{tabular}

Fonte: Adaptado de Schwartz et al. (2012).

Quadro 1. Os 19 valores pessoais na teoria refinada

Alguns estudos complementares sobre a teoria de valores pessoais (Schwartz \& Butenko, 2014; Maxim et al., 2018; Lee et al., 2019), buscaram aplicá-la na prática, e salientaram a importância do modelo na construção do conhecimento e robustez da teoria diante das análises sobre o comportamento humano. Sobre estudos desenvolvidos na perspectiva do comportamento do consumidor em alimentos, não especificamente sobre cafés em cápsulas, e que utilizaram a teoria de Schwartz (1992; 2017) como abordagem, algumas pesquisas demonstraram a coerência e aplicabilidade para as áreas acadêmica e gerencial, identificando as motivações e percepções de consumo do indivíduo e os valores pessoais (Ha \& Jang, 2013; Lang \& Lemmerer, 2018; Gandia et al., 2018; Castro et al., 2019).

\section{Abordagem cadeia meios-fim}

As perspectivas teóricas da cadeia meios-fim são utilizadas em pesquisas em marketing, das quais permitem ao pesquisador compreender e descrever o comportamento decisório do consumidor em relação ao produto (Cardoso Sobrinho et al., 2010). A teoria propõe que os consumidores utilizam estrategicamente os atributos de um produto ou serviço, bem como os benefícios ou consequências obtidas após o consumo como um meio para conseguir atingir objetivos ou estágios finais de existência, ou seja, os fins desejados pelo consumidor (Gutman, 1982; Ikeda et al., 2014; Castro et al., 2019).

Os pensamentos são organizados de forma hierárquica, ligando pensamentos concretos sobre o produto à níveis mais altos de abstração, referente ao autoconhecimento do consumidor. Deste modo, surge uma espécie de cadeia, ligando os atributos do produto ou serviço, sendo eles: concretos ou abstratos - os quais se caracterizam pelos baixos níveis de abstração; aos benefícios/consequências - podendo ser categorizadas como: funcionais ou psicossociais; e os valores pessoais - podendo ser 
instrumentais e/ou terminais. As ligações entre atributos (A), consequências (C) e valores (V), oriundos, inconscientemente, dos níveis mais abstratos do indivíduo em seu contexto de consumo (Gutman, 1982; Walker \& Olson, 1991; Vilas Boas et al., 2006; Ikeda et al., 2014). A Quadro 2 relata de forma dinâmica um modelo conceitual da teoria cadeia meios-fim:

\begin{tabular}{|c|c|c|c|}
\hline Categorias & Definiç̧̃̃es & Níveis & Ilustração \\
\hline \multirow{2}{*}{ Produto } & $\begin{array}{l}\text { Concreto - são as peculiaridades físicas e } \\
\text { palpáveis do produto; }\end{array}$ & \multirow{3}{*}{ 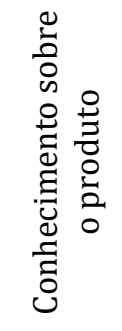 } & \\
\hline & $\begin{array}{l}\text { Abstratos - são as peculiaridades } \\
\text { intangíveis do produto; }\end{array}$ & & \\
\hline \multirow{2}{*}{$\begin{array}{l}\text { Benefícios ou } \\
\text { consequências }\end{array}$} & $\begin{array}{l}\text { Funcionais - são aspectos tangíveis } \\
\text { resultantes após a experiências com } \\
\text { produto; }\end{array}$ & & \\
\hline & $\begin{array}{l}\text { Psicossociais - são os resultados } \\
\text { intangíveis sejam eles psicológicos ou } \\
\text { sociais obtidos após a experiência com o } \\
\text { produto; }\end{array}$ & \multirow{3}{*}{ 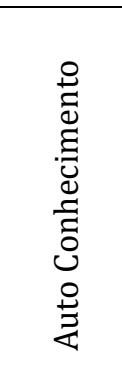 } & \\
\hline \multirow{2}{*}{ Valores } & $\begin{array}{l}\text { Instrumentais - são atitudes e modos } \\
\text { comportamentais para atingir objetivos } \\
\text { finais }\end{array}$ & & \\
\hline & $\begin{array}{l}\text { Terminais - são representações e/ou } \\
\text { condições finais de existência. }\end{array}$ & & \\
\hline
\end{tabular}

Fonte: Adaptado de Vilas Boas et al. (2006).

Quadro 2. Escala de Abstração da Cadeia Meios-fim

As relações psicológicas entre os produtos ou serviços e o cliente podem ser percebidas nas motivações e satisfações dos consumidores, após ao obter vantagens, conquistar objetivos ou saciar os valores e crenças que modificam suas ações de consumo (Walker \& Olson, 1991). Alguns estudos demonstraram a aplicação da teoria meios-fim, inclusive discutindo as relações com a teoria de valores pessoais de Schwartz (1992; 2017). Estas pesquisas mostraram resultados expressivos quanto a capacidade de compreender o comportamento do consumidor diante do consumo, utilizando diferentes produtos como objeto de pesquisa e análise (Vilas Boas et al., 2006; Pimenta et al., 2012; Gandia et al., 2018; Castro et al., 2019). Estes autores conseguiram demonstrar a cadeia de meios e fins como um modelo que visa explicar a relação entre a seleção de um produto que pode facilitar o alcance de estados finais desejados pelo consumidor. Dessa forma, a teoria meios-fim torna-se uma abordagem condizente aos objetivos a serem analisados neste trabalho.

\section{Consumo de café em cápsulas}

As alterações do cotidiano, influenciadas por questões sociais, econômicas, tecnológicas tem provocado alterações sobre o perfil dos consumidores de cafés. Os consumidores se tornaram conhecedores sobre a cultura do café, suas origens e suas variedades de sabores e preparos (Guimarães et al., 2019). Esta transformação do consumidor impulsionou a criação de novas formas de consumo tornando-se uma forte tendência de mercado (ABIC, 2019). Em casa, as máquinas de preparo conquistaram espaço e facilitaram o acesso e consumo de cafés em monodoses. A praticidade e a comodidade ofertada, juntamente com a fácil acesso às novidades acerca de sabores, aromas e blends de cafés (Gandia et al., 2018).

O consumo de café passou por algumas fases, conhecidas como 'ondas' (Guimarães, 2016). A primeira onda se caracterizou pela abertura da commodity ao mercado, impulsionada por fatores ligados à revolução industrial, avanços produtivos, processamento, embalagens, comercialização e o armazenamento do produto. Isso proporcionou um aumento na vida útil do café, bem como em facilidades quanto a distribuição à longas distâncias, impulsionado o consumo global. A segunda onda teve início na década de 60 . A postura produtiva artesanal possibilitou a inserção de um novo conceito 
sobre origem, diferenciação, processos de torrefação, os quais visam atingir diferentes perfis de bebidas, como os cafés em cápsula e o as cafeterias especializadas. Já na terceira onda do café percebeu-se a massificação e a alta padronização dos cafés. Os consumidores passaram a buscar maiores índices de qualidade e diferenciação do produto, se atentando às novas técnicas de produção e processos artesanais, lotes exclusivos, bem como a comercialização diferenciada entre a cadeia produtiva e consumidores (Guimarães, 2016; Samoggia \& Riedel, 2018; Guimarães et al., 2019).

No que tange as modalidades de preparo, o mercado de café em cápsula brasileiro seguirá crescendo de forma acelerada até 2021, mas o produto ainda está em fase de crescimento no Brasil. Por outro lado, o consumidor brasileiro está percebendo o valor dos cafés premium em outros formatos, sejam eles: moído ou em grãos. Neste sentido, as grandes indústrias do mercado de cápsulas começaram a lançar produtos exclusivos, a fim de proporcionar novos lançamentos de máquinas e bebidas diferenciadas (Silva, 2017; Gallotti et al., 2017).

Conceição et al., (2017) afirmam que a quebra de patente quanto às cápsulas ocorrida em 2013, impulsionou novos entrantes no mercado estimulando a concorrência que, por consequência, contribuiu para a redução gradativa nos preços. Ainda segundo os autores, o preço era fator determinante para o consumo de cafés em cápsulas, o que influenciava as tomadas de decisão dos players. 0 mercado era considerado diferente em relação a produção industrial, a logística e alto investimento em tecnologias e inovação (Gallotti, et al., 2017).

Com o dinamismo social e as mudanças nos hábitos dos consumidores, contribuiu para a prática no consumo de café através das cápsulas. A busca por conveniência e praticidade impulsionaram o consumo dessa modalidade, e isso transformou este nicho em uma das tendências de mercado no ano de 2015 e 2017 (ABIC, 2015; 2017; 2019). Assim, fatores como: o símbolo de conveniência, tecnologia, expressão de identidade, a variedade, a facilidade de escolha do alimento e o senso de modernidade, jogam em favor do consumo deste produto. Para tanto, no Brasil, o consumo de máquina de bebida em cápsula é visto como uma tentativa de busca à uma vida melhor, prazer e satisfação para os consumidores (Gandia et al., 2018)

\section{METODOLOGIA}

Este tópico descreve os procedimentos metodológicos adotados para atender os objetivos do estudo e, assim, compreender as peculiaridades que circundam o consumo de café em cápsula. A partir disso, se fez uso da técnica de entrevista em profundidade, semiestruturada, laddering, a qual possui como característica a construção da matriz de implicação e do mapa hierárquico de valores (MHV) (Reynolds \& Gutman, 1988) para o processo de análise dos dados. Sendo assim, esta pesquisa é considerada de natureza qualitativa e descritiva.

No que tange a construção da matriz de implicação e do mapa hierárquico de valores (MHV) se fez uso do software LadderUX® (Gandia et al., 2018). Além disso, o presente estudo também contou com o uso das técnicas projetivas: foto-elicitação e conclusão (Donoghue, 2000; Sresnewsky et al., 2018). As técnicas de conclusão, consistem em solicitar aos entrevistados a completarem uma frase conforme sua concepção, após se inserir em uma possível experiencia ao contexto apresentado naquele momento (Donoghue, 2000). Assim, as técnicas projetivas atuaram de maneira conjunta e complementar a técnica laddering.

Alguns estudos já fizeram o uso de técnicas projetivas quanto ao consumo de cafés (Maximino, 2018; Mello et al., 2020). As técnicas projetivas são mecanismos utilizados visando se sobressair em possíveis dificuldades que venham existir durante o processo de comunicação (Donoghue, 2000). Sresnewsky et al., (2018) relata que o uso de imagens, quando comparadas apenas ao uso de palavras, são capazes de despertar gatilhos profundos na consciência do indivíduo. 0 uso das técnicas projetivas em pesquisas em marketing e comportamento de consumo criam estímulos, estruturados ou não, os quais são adaptados para a obtenção de informações (Donoghue, 2000; Sresnewsky et al., 2018). Sendo assim, retiradas da plataforma Google imagens $®$, quatro imagens foram selecionadas por meio da string de busca: "consumidores de café". A Figura 2 apresenta as quatro imagens selecionadas e adaptadas para este estudo: 

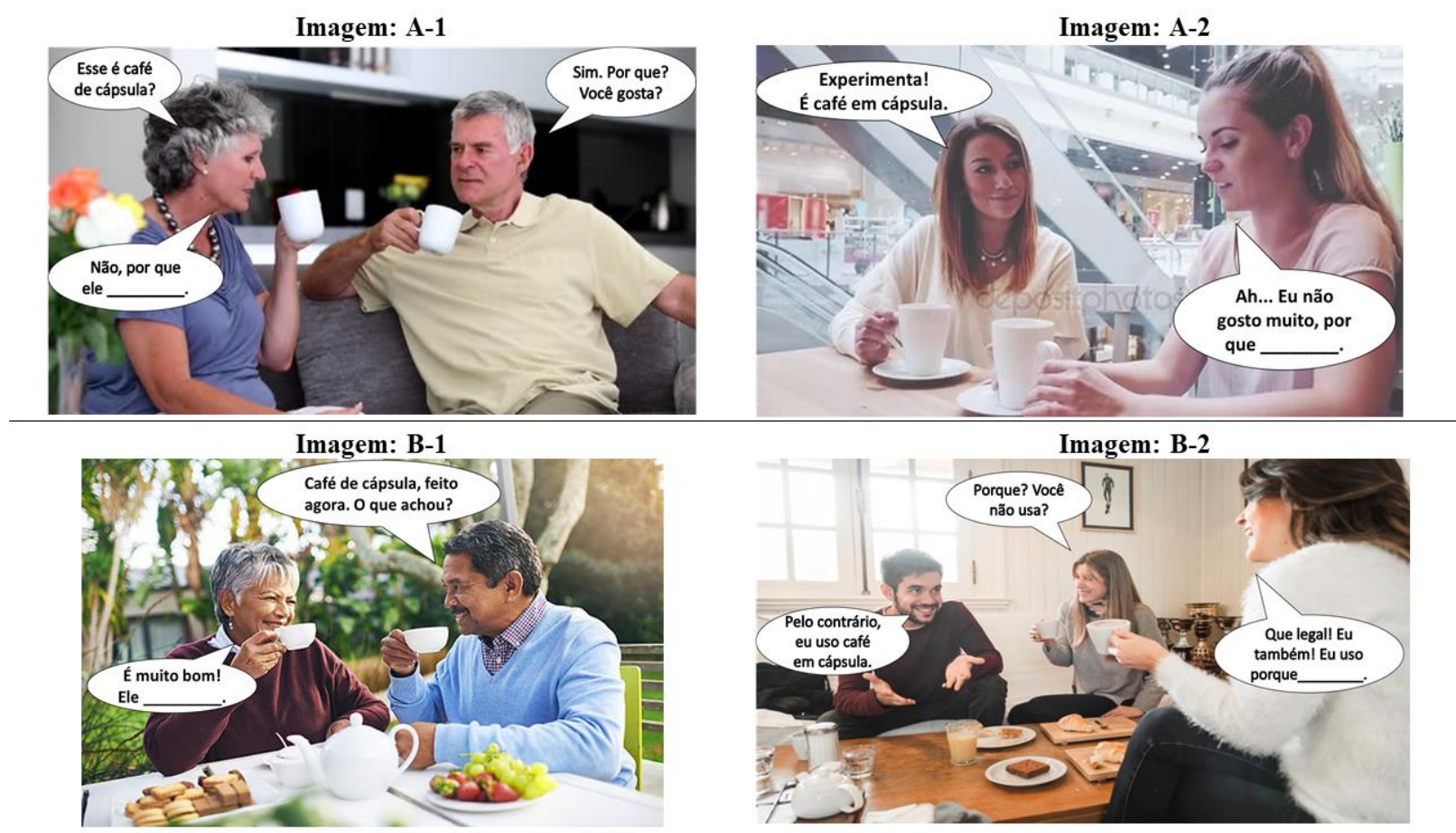

Fonte: Dos autores (2020).

Figura 2. Técnicas projetivas (foto-elicitação e conclusão)

Visando minimizar as influências quanto a faixa etária, duas, das quatro imagens selecionadas e utilizadas neste estudo, apresentam pessoas mais jovens, ao contrário das outras. As técnicas projetivas visam estimular as pessoas a si colocarem em determinadas situações, relatando suas percepções. 0 uso de imagens com pessoas de diferentes faixas de idade, bem como os diferentes contextos de consumo e relações pessoais inferidas pelas quatro imagens selecionadas possuíam o objetivo de facilitar o entendimento para o entrevistado

Salienta-se que para identificar características do produto que desagradam os consumidores, as quais poderiam não ser mencionadas, utilizou-se de estímulos estruturados. Por um lado, as frases de duas imagens (B1 e B2) transpareciam um contexto de comunicação 'positivo' e 'otimista' referente ao consumo de café em cápsula. Por outro, duas imagens (A1 e A2) continham frases que inferiam uma comunicação 'pessimista' e 'sisudo' sobre o consumo da bebida. Em outras palavras, as técnicas projetivas retratando diferentes contextos e relações pessoais relacionados ao consumo, continham frases incompletas de modo a obter características do café em cápsula considerados negativas e positivas pelos entrevistados.

Todos os termos (positivos e negativos) relatados pelos entrevistados serviram como base para a realização das entrevistas em profundidade. Ou seja, foram consideradas como atributos (concretos ou abstratos) e utilizados como ponto de partida para realização da técnica laddering. Além disso, todos termos foram utilizados para a construção de uma nuvem de palavras, evidenciando sua relevância conforme o número de vezes que foram citados. Assim, quanto mais vezes foi citado, maior o seu tamanho na nuvem de palavras (Figura 3).

No que se refere a laddering, a técnica possui o objetivo atingir níveis maiores de abstração do consumidor sobre ao produto. A soft laddering, usada neste estudo, consiste em modelo de entrevista em profundidade, semiestruturada, realizada face a face (Cardoso Sobrinho et al., 2010), capaz de fazer com que o entrevistado faça uma reflexão profunda e imersiva perante às suas motivações de consumo. A técnica se caracteriza pelo uso de perguntas como: "por que isto é importante para você?" (Reynolds \& Gutman, 1988) e "como você se sente?" (Chema et al., 2006). Assim, a laddering descreve, por meio do MHV, a representação estrutural de forma hierárquica sobre a sistema cognitivo que orienta o consumo de café em cápsula. Retratando os aspectos que orientam a decisões dos 
consumidores sobre o consumo do produto, identificados pela relação entre atributos (A), consequências (C) e valores (V) (Reynolds \& Gutman, 1988; Ikeda et al., 2014).

Quanto a seleção dos entrevistados, alguns critérios foram estabelecidos como base, de forma a selecionar apenas consumidores assíduos de café em cápsula, sendo eles: a) o participante deveria possuir uma máquina de bebida (de monodoses) em sua posse, b) o participante deveria estar consumindo a bebida por um período superior a 12 meses, e; c) consumir pelo menos duas cápsulas de café por semana. Ainda para seleção dos entrevistados, utilizou-se do método Snowball (bola de neve), em que os entrevistados indicam outros consumidores do produto para participar da pesquisa (Vinuto, 2014). 0 encerramento das 21 entrevistas seguiu as recomendações quanto aos critérios de saturação (Guerra, 2006).

Foram realizadas 21 entrevistas, as quais ocorreram no segundo semestre de 2019. Destas, 15 foram realizadas presencialmente, enquanto outras 06 foram realizadas por videoconferência, por meio de softwares como: Skype (4 entrevistas) e WhatsApp Vídeo (2 entrevistas). De acordo com Janghorban et al. (2014), a realização de pesquisas individuais com o uso do software Skype pode ser utilizada de forma complementar. Sendo assim, devido à similaridade entre os softwares, torna-se plausível o uso do WhatsApp Vídeo. As vantagens pelo uso de software de vídeo suprem suas desvantagens, pois permitem ao entrevistado uma melhor comodidade e disponibilidade de tempo (Gandia et al., 2018). Juntas, as entrevistas totalizaram 456 minutos de gravação, as quais todas foram transcritas.

De posse das transcrições, inicia-se o processo de análise e interpretação dos dados. Todas as entrevistas transcritas passaram pelo processo de categorização e codificação. Ou seja, consiste na criação de termos-chave, palavras mestras, em que representam de forma ampla as declarações dos entrevistados. Reynolds e Gutman (1988) recomendam o uso entre 30 a 50 elementos, os quais possam se retratados na matriz de implicação. Os códigos e categorias criadas foram retratadas em um quadro-resumo e quantidade de relações (diretas e indiretas) entre os elementos foram retratadas na matriz de implicação.

As relações entre atributos (A), consequências (C) e valores (V) de maior recorrência foram expressas de forma gráfica pelo mapa hierárquico de valores (MHV) (Reynolds \& Gutman, 1988; Ikeda et al., 2014). Salienta-se que, a matriz de implicação e o MHV somente foram obtidos após a inserção das ladders obtidas dos entrevistados no software LadderUX®. Por fim, é identificado a cadeia de percepções dominante, bem como os elementos centrais na relação entre $A \rightarrow C \rightarrow V$. Sendo que os valores pessoais foram analisados e interpretados sob a ótica da teoria dos valores pessoais (Schwartz, 2017).

\section{ANÁLISES E RESULTADOS}

Quanto as características sociodemográficas e de consumo dos entrevistados, 52,38\% (11) foram do sexo masculino e 47,62\% (10) do sexo feminino. Além disso, a frequência média de consumo dos entrevistados foi acima três cápsulas por semana $(3,09)$, o que indica uma boa relação de consumo com o produto. Por outro lado, o tempo de experiência média geram de consumo foi acima de dois anos (02 anos e 07 meses).

Ao iniciar as entrevistas com o uso das técnicas projetivas, foi possível identificar as características inerentes ao café em cápsula consideradas relevantes para os participantes consumidores. Inicialmente, identificou-se aquelas que despertavam percepções positivas e, em seguida, as percepções negativas sobre o produto. A partir disso, todas os termos citados forram contabilizados de modo a construir uma nuvem de palavras. Sendo assim, a Figura 3 retrata as características consideradas positivas e negativas pelos participantes em relação ao café em cápsula. Assim, os termos de maior recorrência e, por consequência, mais relevantes para os consumidores foram destacados: 


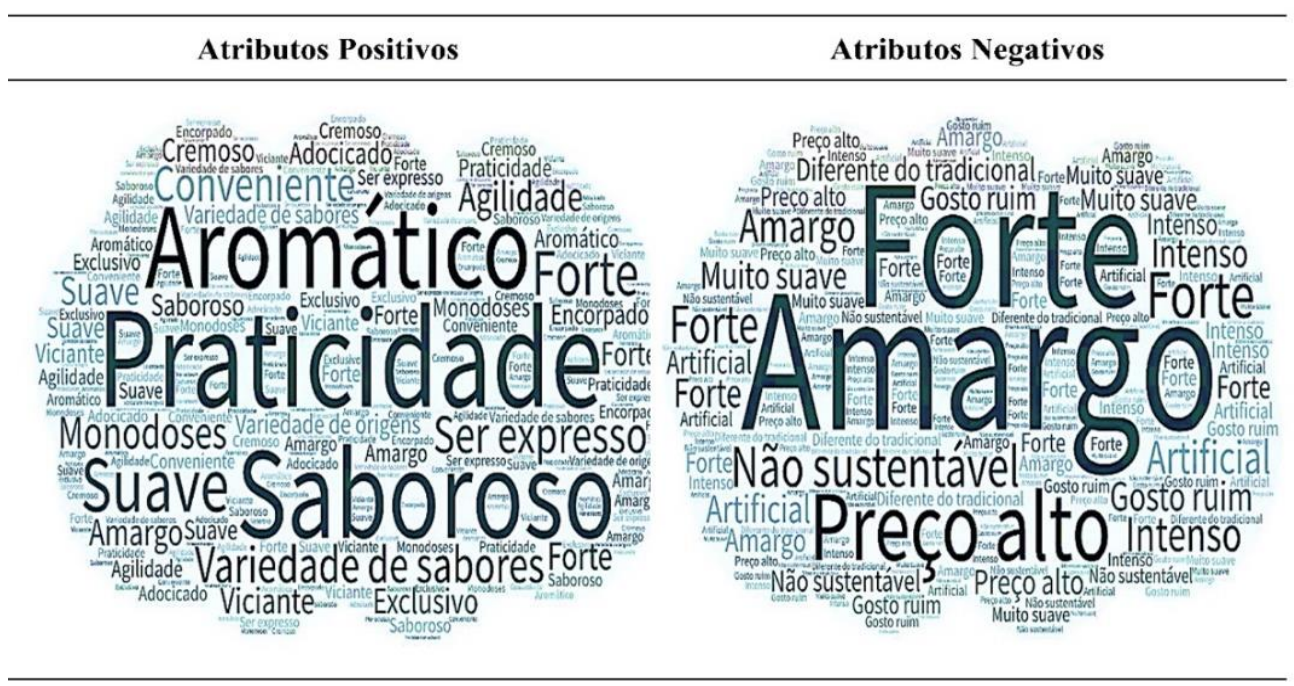

Fonte: Dos autores (2020).

Figura 3. Nuvem de palavras referente aos atributos do produto

As características citadas pelos entrevistados nas técnicas projetivas foram utilizadas como ponto de partida para a realização das entrevistas em profundidade conforme os pressupostos da técnica laddering. Após a realização, bem como a transcrição de todas as entrevistas, tem-se o início a análise de conteúdo, categorizando as informações obtidas (declarações dos entrevistados) em termos chave de acordo com sua similaridade e, assim, seguir para a codificação. Tais categorias codificadas são responsáveis por resumir, de forma objetiva, as principais frases relatadas pelos entrevistados sobre os atributos do produto, as consequências advindas pelo consumo e os objetivos finais de existência (valores pessoais).

Salienta-se que na apresentação da matriz de implicação, Reynolds e Gutman (1988) recomendam o uso de 30 a 50 elementos. Sendo assim, 35 categorias foram criadas, as quais se dividem em: 12 atributos ( 5 concretos e 7 abstratos), 15 referentes aos benefícios e/ou consequências ( 5 funcionais e 10 psicossociais) e 8 valores ( 5 instrumentais e 3 terminais), os quais são ilustrados pela Tabela 1.

De posse das categorias codificadas, bem como as 66 ladders obtidas por meio das declarações e relatos dos 21 consumidores de café em cápsula, tem-se a criação da matriz de implicação. A matriz de implicação consiste em uma matriz quadrada, a qual representa quantitativamente todas as ligações diretas (à esquerda da célula) e indiretas (à direita na célula) existentes entre as categorias (Reynolds \& Gutman, 1988). Em outras palavras, a matriz contabiliza e representa todas as relações entre as células existentes, as quais se referem às ligações entre os atributos, consequências e valores. Para isso, utilizou-se do auxílio do software LadderUX, facilitando a identificação do número de vezes que cada categoria levou à outra e assim por diante (ver Tabela 2 no Apêndice).

Com a construção da matriz de implicação pelo sofware LadderUX, o mapa hierárquico de valor (MHV) foi gerado automaticamente. Segundo Reynolds e Gutman (1988), o MHV se caracteriza pela apresentação gráfica das relações mais relevantes existentes entre as categorias. Para os autores, é recomendável que o ponto de corte resulte em uma representação de aproximadamente $2 / 3$ do volume total do número de relações. Sendo assim, apenas as relações iguais ou acima do ponto de corte estabelecido são selecionadas. Consequentemente, isso permite ao pesquisador uma melhor compreensão sobre o pensamento, de forma hierarquica, do consumidor sobre o café em cápsula. 
Tabela 1

Lista de categorias e códigos

\begin{tabular}{ll}
\multicolumn{1}{c}{ Atributos concretos } & Consequências psicossociais \\
\hline 1- Monodoses & 18- Otimizar tempo \\
2- Não sustentável & 19- Sentir-se tranquilo e bem-humorado \\
3- Variedade & 20- Criar diferenciação e status \\
4- Origem & 21- Sentir-se mal-humorado ou com mal-estar \\
5- Características da bebida & 22- Sentir-se motivado \\
\hline Atributos abstratos & 23- Sentir-se produtivo e concentrado \\
\hline 6- Preço Alto & 24- Sentir satisfação e bem-estar \\
7- Sabor & 25- Não prejudicar a saúde \\
8- Pior qualidade & 26- Facilita a socialização \\
9- Exclusivo e luxuoso & 27- Cria chateação e tristeza \\
10- Praticidade e conveniência & Valores instrumentais \\
11- Aroma & 28- Hedonismo \\
12- Preço baixo & 29- Prestígio \\
\hline Consequências funcionais & 30- Autodireção pensamento \\
\hline 13- Desenvolve o paladar & 31- Autodireção - ação \\
14- Aumenta a experiência e o consumo & 32- Benevolência - carinho \\
15- Diminuição do consumo & Valores terminais \\
16- Poupar recursos & 33- Estimulação \\
17- Otimizar tarefas & 34- Segurança - pessoal \\
\hline Fon & 35- Realização \\
\hline
\end{tabular}

Fonte: Dos autores (2020).

Neste estudo, o ponto de corte adotado foi de três relações. Considera-se que o MHV com o ponto de corte três resultou em uma melhor visualização gráfica e representação das relações mais recorrentes entre $\mathrm{A} \rightarrow \mathrm{C} \rightarrow \mathrm{V}$. Deste modo, com o referido valor de uso no ponto de corte, o MHV apresentou 379 ligações (152 diretas e 227 indiretas), representando 57,51\% do volume total de ligações igual ou superior ao nível de corte estabelecido. A representação gráfica construída da estrutura hierárquica cognitiva dos consumidores de café em cápsula é retratada na Figura 4, ilustrando as relações relevantes entre os atributos do produto (A), as consequências ou benefícios advindos do consumo (C) e sua conexão com valores pessoais (V).

Com a criação do mapa hierárquico de valores (MHV), torna-se necessário identificar as cadeias de percepções dominantes. Reynolds e Gutman (1988) relatam que ao observar o MHV da base ao topo, qualquer caminho pode se apresentar como um potencial de percepção dominante. Sendo assim, torna-se necessário identificar dentre as cadeias obtidas, qual contribui em maior grau para a construção do mapa (Oliveira \& Ikeda, 2004) e, assim, compreender as percepções dos consumidores. Sendo assim, a cadeia com o maior volume de de relações diretas e indiretas é composta pelas relações: 3-7-10-17-18-19-22-23-24-28-31-35, a qual é destacada (vermelho).

Entretanto, quanto maior a extensão e, consequentemente, os números de elementos presentes na cadeia, maior a tendência de a quantia de relações ser superior as cadeias com menos elementos (Vilas Boas, 2005). Para Vilas Boas (2005), dada as proporções, a importância das cadeias formadas por números menores de categorias também deve ser levada em consideração. Sendo assim, o autor utiliza uma forma de análise, em que as cadeias são separadas em grupos e em função do número de categorias compostas, o que que resulta na identificação das cadeias de percepções dominantes referentes a cada grupo. 


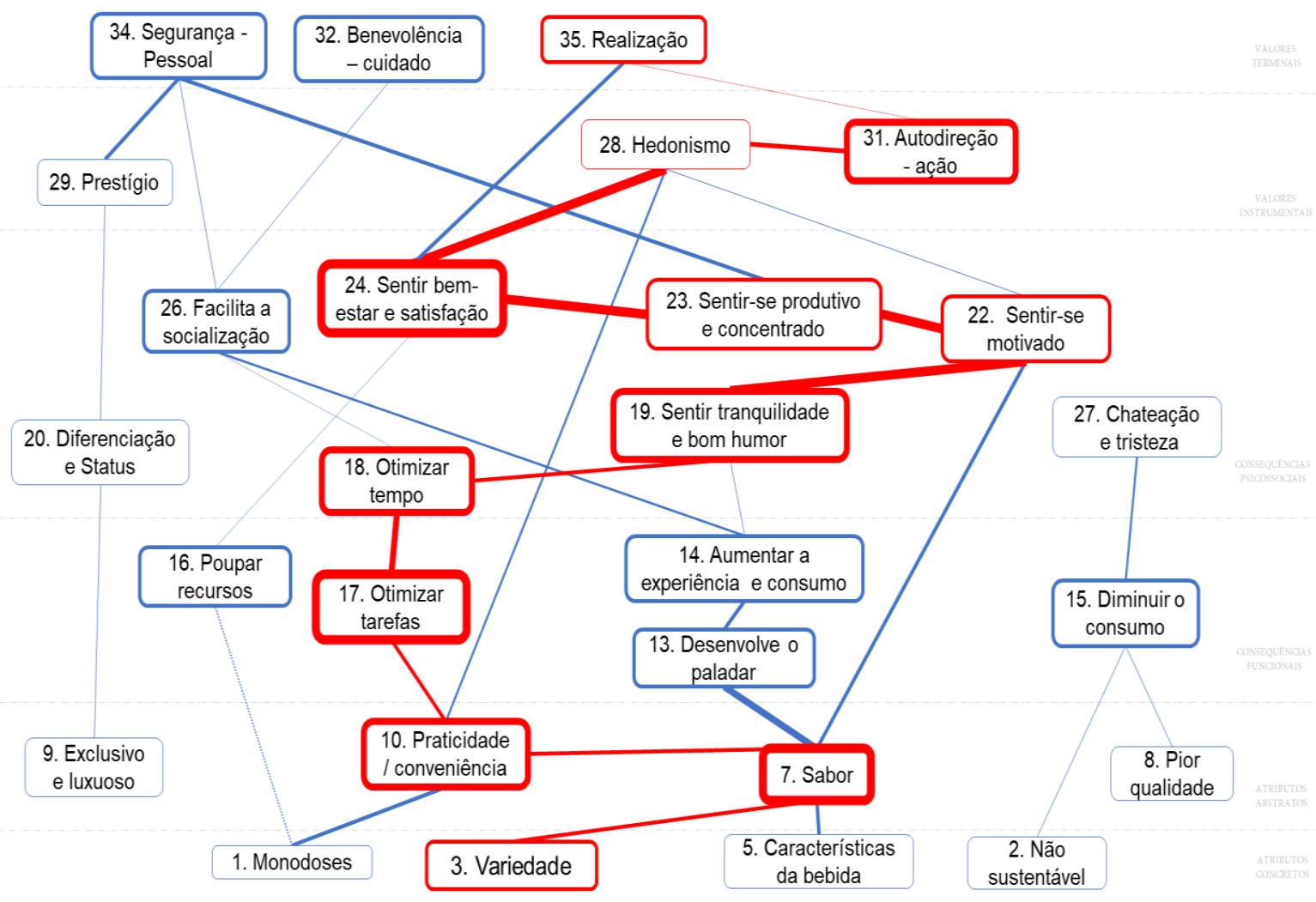

Fonte: Dos autores (2020) - auxílio do Software LadderUX.

Figura 4. Mapa Hierárquico de Valor (ponto de corte: 3)

A partir disso, todas as 46 cadeias identificadas foram divididas em grupos com 3 a 12 categorias. Foi criada uma 'pequena matriz quadrada' para cada cadeia em cada grupo e, assim, foi realizado o somatório das relações (diretas e indiretas) referente a cada uma das cadeias.

Tabela 3

Representantes dos grupos das cadeias de percepções dominantes

\begin{tabular}{clccc}
\hline $\begin{array}{c}\text { No de } \\
\text { elementos }\end{array}$ & \multicolumn{1}{c}{ Cadeias } & $\begin{array}{c}\text { Relações } \\
\text { Diretas }\end{array}$ & $\begin{array}{c}\text { Relações } \\
\text { Indiretas }\end{array}$ & $\begin{array}{c}\text { Total de } \\
\text { relações }\end{array}$ \\
\hline 12 & $3-7-10-17-18-19-22-23-24-28-31-35^{*}$ & 120 & 215 & 335 \\
\hline 11 & $1-10-17-18-19-22-23-24-28-31-35$ & 105 & 162 & 267 \\
\hline 10 & $3-7-10-17-18-19-22-23-24-35$ & 89 & 145 & 234 \\
\hline 9 & $1-10-17-18-19-22-23-24-35$ & 74 & 107 & 181 \\
& $3-7-10-17-18-19-22-23-34$ & 75 & 105 & 180 \\
\hline 8 & $1-10-17-18-19-22-23-34$ & 61 & 75 & 136 \\
\hline 7 & $3-7-10-17-18-26-34$ & 61 & 51 & 80 \\
\hline 6 & $1-10-17-18-26-34$ & 40 & 40 & 75 \\
& $1-10-17-18-26-32$ & 42 & 33 & 73 \\
\hline 5 & $3-7-22-23-24-35$ & 24 & 49 & 37 \\
\hline 4 & $3-7-22-23-34$ & 14 & 23 & 23 \\
\hline 3 & $8-16-24-35$ & 9 & 14 & 15 \\
\hline
\end{tabular}

Fonte: Dos autores (2020). Nota: ${ }^{*}$ cadeia com maior volume de relações (diretas e indiretas).

Em seguida, o valor obtido sobre cada cadeia foi novamente somado ao resultado obtido das demais cadeias pertencentes ao grupo. Assim, a somatória total das relações do grupo (bloco) foi dividida pelo número de cadeias pertencentes ao grupo. Deste modo, o valor médio obtido foi usado 
como ponto de corte para descartar as demais cadeias com valores inferiores. Tal processo foi realizado duas vezes e o resultado obtido é ilustrado pela Tabela 3.

Na primeira análise, 23 cadeias foram removidas. No entanto, visando um resultado ainda mais conciso foi realizado uma segunda análise, a qual resultou em 13 cadeias de percepções dominantes que foram descritos na Tabela 3. A partir dos resultados obtidos na análise dos dados e no MHV iniciase a sessão de discussão.

\section{DISCUSSÃO}

O uso das técnicas projetivas resultou em um número de características (atributos) considerados positivos relativamente maior, quando comparado aos aspectos negativos relatados pelos consumidores durante as técnicas projetivas. A justificativa para esse baixo número de atributos considerados negativos pode estar relacionada ao uso da técnica foto-elicitação de viés negativo junto a participantes com alta identificação e relação com o produto. Sendo assim, os entrevistados encontraram dificuldades para relatar características negativas referentes ao produto e, consequentemente, prejudicando a eficácia de uso da técnica quanto a esse objetivo.

A nuvem de palavras construída a partir dos termos obtidos com o uso das técnicas projetivas, três características apresentaram destaque de maneira negativa, como o alto preço, forte e amargo. Percebe-se que os consumidores entrevistados relataram os sabores forte e/ou amargo como atributos negativos do produto. Apesar das percepções e sensibilidades gustativas variarem conforme as particularidades físicas da bebida e consumidor, percebe-se a relevância do uso de escalas nas embalagens dos cafés em cápsula. De acordo com tais declarações, o uso de estratégias que visam classificar, de forma clara, os níveis de intensidade e consistência podem ser benéficos aos produtores da bebida. Estas estratégias servem como um indicativo àqueles que não utilizam deste mecanismo de informação, já que os consumidores estão cientes sobre tal aspecto.

Outra característica negativa retratada se refere ao preço elevado, já que os entrevistados alegam que o preço praticado se torna um empecilho. Gerar estratégias de forma a transmitir a relação positiva entre custo e os benefícios obtidos pelo consumo pode agregar valor à marca. Os consumidores relatam que a existência referente as condições especiais de comércio e precificação são preferidas. Sendo assim corrobora com a criação de combos e lotes, promoções e a criação de clubes de assinatura, estratégias estas já utilizadas por algumas empresas no mercado. Mesmo com a quebra da patente das cápsulas de bebidas monodoses em 2013 e, por consequência, a entrada de novas empresas no mercado e a queda nos valores de produção e comercialização (Conceição et al., 2017), percebe-se que os consumidores ainda consideram que os valores dos cafés em cápsulas são elevados para o consumo.

A falta de sustentabilidade ambiental também apareceu como algo negativo na nuvem de palavras sobre o consumo de cápsulas de café. Os consumidores consideram que o excesso de cápsulas resultantes das práticas de consumo prejudica o meio ambiente. Sendo assim, a cadeia agroindustrial do produto precisa trabalhar alternativas quanto as formas de coletas seletivas, bem como aprimorar as políticas de logística reversa, principalmente, em pequenas cidades. Apesar de prejudicar a praticidade do consumo, a opção de venda dos cafés em conjunto com cápsulas reutilizáveis, bem como as vendas do produto em cápsulas biodegradáveis, podem ser uma boa alternativa. Ademais, a promoção de campanhas de preservação ambiental, associadas ao produto, também podem ser uma alternativa.

Dentre o número de características (atributos) obtidas pelas técnicas projetivas, as quais foram consideradas positivas sobre o produto, três foram amplamente destacadas pelos entrevistados: a praticidade, o sabor e o aroma. Os consumidores valorizam as facilidades relacionas ao preparo e ganho de tempo, bem como para obter tipos diferentes de sabores por meio das cápsulas de café. 0 sabor dos cafés em cápsula, bem como o aroma obtido mediante o preparo se apresentaram de forma positiva quanto a as motivações no consumo do produto.

Quanto a técnica laddering, o MHV (Figura 4) retratou que a cadeia de percepções dominante é composta pelas relações entre as categorias: 3-7-10-17-18-19-22-23-24-28-31-35 (Tabela 3). Deste modo, é possível identificar que o atributo abstrato mais relevante para os consumidores, se refere a 
variedade (item 3). Ou seja, os tipos e origens de grãos que as cápsulas de café são capazes de fornecer no mercado. Tais características estão intimamente ligadas aos sabores (item 7) experienciados, bem como a praticidade e conveniência (item 10) obtidos pelos consumidores. É possível observar que o consumidor valoriza a possiblidade de apreciar os diferentes tipos de cafés em cápsula e, consequentemente, seus sabores. Ainda, atribuem grande relevância quanto as preparações fáceis e rápidas, as quais não despendem grande esforço físico e de tempo na hora do preparo e consumo da bebida.

No que tange as consequências e benefícios identificados na cadeia de percepções dominante, o consumo do produto está atrelado à capacidade de otimizar as tarefas (item 17) do cotidiano para seus consumidores. 0 que resulta nas consequências psicológicas de estar otimizando e criando mais tempo (item 18) no dia, gerando sensações de tranquilidade e bom humor (item 19) e motivação (item 22). Tais aspectos influenciam positivamente a produtividade e concentração do consumidor durante a realização de suas tarefas (item 23), ocasionando em sentimentos de satisfação e bem-estar (item 24).

Assumindo o papel de moderador sobre as ações de compra e consumo dos cafés em cápsulas tem-se os valores instrumentais e terminais. Por meio da cadeia de percepções dominante, os sentimentos de satisfação e bem-estar (item 24) estão associadas as sensações de prazer e alegria (28 - Hedonismo). Tal valor também ser relaciona com a autodireção em ação (item 31). Ou seja, para os consumidores a autonomia em poder realizar suas atividades, fazer suas próprias escolhas está intimamente ligado aos sentimentos de prazer, e indiretamente ligada aos sentimentos de satisfação e bem-estar. Logo, a cadeia de percepções dominantes termina no valor terminal de realização (item 35), conforme a lista de Schwartz (2017). Em outras palavras, os consumidores de café em cápsulas valorizam a liberdade em executar suas ações, de modo a atingir o estágio final de realização pessoal.

Observando as demais cadeias de percepções dominantes obtidas por meio dos grupos de categorias, algumas relações relevantes não foram identificadas na cadeia com maior volume de relações (diretas e indiretas). Sendo assim, o atributo concreto 01 (monodoses) está associado a praticidade e conveniência (item 10) e a poupar recursos (item 16). Ou seja, para o consumidor as facilidades obtidas se referem a possibilidade do prepara e consumo individual, a qual também contribui para evitar desperdícios de produto e, consequentemente, dinheiro.

Outra relação observada se refere a otimização de tempo (item 18), o qual facilita a socialização (item 26). Para o consumidor é possível fornecer um café de preparo ágil em momentos de interações sociais, o que demonstra a relação entre os aspectos ligados as relações de partilhar (informações ou experiências humanas) em contextos familiares ou profissionais, as quais podem ser impulsionadas pelo consumo do produto. Motivados pela busca em agradar pessoas próximas (32 benevolência de cuidado) ou obtenção de pertencimento e segurança (34 - segurança pessoal). Todavia, os valores de segurança pessoal (item 34) e realização (item 35) também são associados a produtividade e concentração (item 23) na realização de tarefas. Em outras palavras, ao consumir o produto e se sentir produtivo e/ou concentrado durante ou após a realização de suas atividades, o indivíduo se sente ainda mais seguro ou realizado.

Observando as cadeias de percepções dominantes referentes a cada grupo e as relações entre atributos e valores (Tabela 3), percebe-se que os atributos concretos monodoses (item 1) e variedade (3), bem como os atributos abstratos sabor (item 7) e praticidade/conveniência (item 10) apresentaram níveis significantes quanto aos valores de segurança pessoal (34) e realização (35). 0 que se torna uma alternativa estratégia de marketing e segmentação de consumidores com base em suas orientações de valor.

É importante dizer que na matriz de implicação foi possível observar o grau de centralidade referente a cada uma das categorias presentes. Sendo assim, o atributo concreto de maior centralidade foi a variedade de opções do produto (item 3), possuindo $2,4 \%$ das relações. Sendo que o sabor (item 7) foi a categoria de maior centralidade $(8,7 \%)$ no que se refere aos atributos abstratos, corroborando com os resultados ilustrados pela Tabela 3. Isso significa que os consumidores de café em cápsula prezam pela possibilidade de experimentar diferentes tipos e, assim, adquirir experiências gustativas sobre o consumo dos cafés. 
A consequências funcionais em conseguir otimizar as tarefas (item 17), foi evidenciada com $8,1 \%$ de centralidade. Isso demonstra o dinamismo que o preparo do produto fornece, resultando em facilidade na realização de outras tarefas, consumindo ou conseguinte ao consumo. A consequências psicossocial de maior índice se refere aos sentimentos de satisfação e bem-estar (item 24), com 7,5\% de centralidade. $O$ que demonstra os efeitos de contentamento advindos pelo consumo do produto.

Os valores instrumentais de autodireção por ação (item 31) apresentou índices de centralidade em níveis de 5,5\%. A autodireção por ação consiste na liberdade do sujeito em realizar exercícios ou atividades, visando atingir aqueles objetivos escolhidos por si próprio (Schwartz et al., 2012). Em suma, o processo de preparação e consumo dos cafés em cápsulas promovem aspectos semelhantes ao livre arbítrio perante a realização de suas atividades e ações cotidianas. 0 estágio terminal de ser de realização (item 35) se apresentou como o mais visado pelos consumidores, já que tal aspecto foi apontado com 2,5\% de centralidade, corroborando com os resultados ilustrados pela Tabela 3.

Para os entrevistados consumidores, a prática de consumo dos cafés em cápsulas é motivada, principalmente, pela praticidade e conveniência ofertada pelo produto. Tais características facilitam o desenvolvimento de suas atividades, por meio do ganho e otimização de tempo. Esses benefícios permitem aos consumidores a sensação de tranquilidade, o que resultar em bom humor e motivação. A razão para isso advém de suas características pessoais, na busca pela liberdade em realizar suas atividades ao seu jeito e, assim, se sentir realizado conforme os padrões de julgamento e anseios sociais. Em outras palavras, se tornar realizado e bem-sucedido, por meio da liberdade de poder determinar suas próprias ações e escolhas são os guias no consumo de café em cápsula.

Sobre as características do produto levantadas como de conotação negativa, percebe-se que a falta de acesso às práticas sustentáveis ao meio ambiente (item 2), bem como o consumo de um produto que possua um sabor (item 7) e características contrárias as particularidades gustativas e preferenciais do indivíduo. Tais aspectos são apresentadas como possíveis entraves que podem prejudicar a comercialização do produto, resultando em consequências funcionais como diminuição de consumo (item 15) e, consequentemente, sentimentos de chateação e tristeza (item 27) dos consumidores.

A inexistência de estratégias comerciais que possam minimizar os aspectos negativos do produto, pode prejudicar o consumo do produto no médio ou longo prazo. Por fim, o MHV conseguiu representar as relações entre os atributos, consequências e valores, evidenciando duas perspectivas distintas: uma positiva e outra negativa. Assim, por se tratar de uma pesquisa de marketing, tais perspectivas apresentam informações relevantes e atrativas aos diversos agentes envolvidos na cadeia produtiva dos cafés em cápsulas.

\section{CONSIDERAÇÕES FINAIS}

A evolução tecnológica está fazendo parte do dia-a-dia do ser humano, influenciando suas preferências, gostos, comportamentos e sentimentos (Solomon, 2016). Sendo assim, os resultados desta pesquisa demonstraram que os consumidores estão propensos a se adequar a modernidade alimentar, bem como a adesão de produtos tecnológicos que promovem praticidades, como, o caso da maquinas de bebidas em monodoses, especialmente os cafés em cápsulas (Gallotti et al., 2017; Gandia et al., 2018).

Os resultados obtidos considerando características tangíveis e intangíveis dos cafés em cápsulas, por meio da análise das entrevistas com os consumidores, podem contribuir para as grandes e pequenas indústrias aprimorarem ou criar novos produtos e, assim, inseri-los ao mercado. Os resultados reforçam que o uso de cápsulas reutilizáveis ou biodegradáveis, as quais são menos agressivas ao meio ambiente, são características valorizadas pelos consumidores e compreendidas com promotoras da sustentabilidade ambiental.

Em outro ponto, percebe-se a importância de diversificar a variedade de grãos, aromas e sabores disponíveis. Neste sentido, ofertar cafés de outras regiões do Brasil e do mundo, lançar produtos exclusivos em parcerias com clubes de assinantes, e criar campanhas publicitarias ligadas a praticidade e conveniência ao preparar da bebida, bem como sobre as influências positivas nas relações pessoais no âmbito familiar ou trabalho, tornam-se um atrativo ao consumidor. 
As consequências funcionais e psicossociais identificadas após o uso do produto, podem contribuir de maneira positiva ao (re)posicionamento de marcas no mercado. A capacidade de otimizar as tarefas e, por consequência, proporcionar uma economia de tempo, despertam sentimentos de satisfação e bom-humor, o que demonstra as vantagens observadas quanto consumo do café em cápsula. No que se refere aos valores pessoais, foi possível identificar a busca dos entrevistados pela sensação de liberdade ao realizar suas tarefas, de forma a gerar sentimentos de realização.

No que se refere as contribuições acadêmicas, a combinação entre as técnicas projetivas e laddering mostrou-se eficaz, principalmente, na obtenção de atributos considerados positivos à adesão do produto. Por outro lado, quando se refere ao objetivo de levantar aspectos negativos, os consumidores com grande afinidade com o produto, ao serem abordados, tendem a demostrar dificuldades em se expressar, conforme foi observado no desenvolvimento da pesquisa. Em outras palavras, pessoas que possuam identificação com o produto sentem dificuldades para apontar características negativas. Além disso, a compatibilidades entre as teorias de Schwartz (1992) e Gutman (1982) se mostrou eficaz quanto ao desenvolvimento e discussão dos resultados da pesquisa, identificando as particularidades que envolve o consumo dos cafés em cápsula. Gerencialmente, a cadeia agroindustrial do café poderá explorar de forma abrangente os resultados aqui expostos, principalmente, no que se refere ao desenvolvimento de estratégias de comunicação. Deste modo, podem explorar os valores pessoais envolvidos no consumo de cafés em cápsulas e criar estratégias e ações para captação de novos consumidores.

Considerando que o estudo foi realizado em uma cidade da mesorregião sul do estado de Minas Gerais. A aplicação deste estudo, englobando outros municípios e estados brasileiros, podendo inclusive, alterar a unidade, podem comprovar e/ou relacionar os resultados deste estudo, tornandose uma alternativa para estudos futuros. Além disso, os resultados obtidos criam a possibilidade de realizar pesquisas de natureza quantitativa, já que elas proporcionam analises globais e, assim, gerar conteúdo para triangulação de resultados. Por fim, o contexto brasileiro é conhecido por sua capacidade agroindustrial, em que trabalhos futuros sobre marketing e comportamento do consumidor na área alimentar podem contribuir tanto para comercialização quanto para a produção de alimentos.

\section{Referências}

Associação Brasileira da Industria de Café [ABIC]. (2019). Cápsula/Histórico. Recuperado em 10 de dezembro de <http://abic.com.br/certificacao/capsula/historico/>.

Associação Brasileira da Industria de Café [ABIC]. Euromonitor Consulting. (2015). Tendências do mercado de cafés em 2017. Encafé, 1-42. Recuperado em 10 dezembro de <https://www.abic.com.br/wp-content/uploads/2020/01/Euromonitor_Coffe-Market-Trendsin-Brazil_-Encafe.pdf>.

Associação Brasileira da Industria de Café [ABIC] (2017). Euromonitor Consulting. Tendências do mercado de cafés em 2017. Encafé, São Paulo, p. 1-42, novembro de 2017. Recuperado em: <https://www.abic.com.br/wp-content/uploads/2020/01/Euromonitor_Coffe-Market-Trendsin-Brazil_-Encafe.pdf>.

Almeida, S. O., Brasil, V. S., Espartel, L. B., \& Callegaro, F. (2015). Limites Éticos e Contribuições para a Sociedade: uma análise das implicações da aproximação entre neurociência e comportamento do consumidor. Revista Economia \& Gestão, 11(40), 87-116.

Brümmer, N., \& Zander, K. (2020). Drivers of organic food choice in Germany-the case of young adults. Organic Agriculture, 10(1), 57-64.

Cardoso Sobrinho, C. A. C., Vilas Boas, L. H. de B., Martins, A., \& Coelho, G. (2010). Uma comparação entre as técnicas hard e soft laddering aplicadas à percepção de valor de acadêmicos de administração em relação a uma instituição de ensino superior na cidade de Rio VerdeGO. Innovation \& Management Review, 7(4), 113-136. 
Castro, Á. L. de O., Vilas Boas, L. H. de B., \& Tonelli, D. F. (2018). Valores Pessoais, Cadeia Meios-Fim, Identidade e Comportamento de Consumo em Alimentos: Uma Revisão Bibliométrica. Revista Brasileira de Marketing, 17(6), 771-787.

Castro, A. L. O., Vilas Boas, L. H. De B., Rezende, D. C., \& Pimenta, M. L. (2019). Behind the wine glass: values that guide consumption in Minas Gerais - Brazil. British Food Journal, 121, 2477-2489.

Chema, S. K., Marks, L. A., Parcell, J. L., \& Bredahl, M. (2006). Marketing biotech soybeans with functional health attributes. Canadian Journal of Agricultural Economics/Revue canadienne d'agroeconomie, 54(4), 685-703.

Conceição, J. C. P. R. da., Ellery Junior, R. G. de., \& Conceição, P. H. Z. da. (2017). Cadeia agroindustrial do café no Brasil: uma análise do período recente. Radar, 53, 25-29.

Donoghue, S. (2000). Projective techniques in consumer research. Journal of Consumer Sciences, 28, 47-53.

Eccles, J. S., \& Wigfield, A. (2002). Motivational beliefs, values, and goals. Annual Review of Psychology, 53(1), 109-132.

Gallotti, M. E. R., Pereira, E., Pinheiro, V., Paulino, S., Peralta, P., \& Câmara, V. B. (2017). Cápsula de café: uma análise com base em teoria da inovação buscando agregar valor à balança comercial brasileira. Cadernos de Prospecção, 10(2), 137.

Gandia, R. M., Sugano, J. Y., Vilas Boas, L. H. de B., \& Mesquita, D. L. (2018). Beverage capsule consumption: A laddering study. British Food Journal, 120(6), 1250-1263.

Guerra, I. C. (2006). Pesquisa qualitativa e análise de conteúdo: sentidos e formas de uso. Estoril: Principia.

Guimarães, E. R. (2016). Terceira onda do café - base conceitual e aplicações. Dissertação de mestrado em Administração, Universidade Federal de Lavras, Lavras, MG, Brasil.

Guimarães, E. R., Leme, P. H. M. V., Rezende, D. C. de., Pereira, S. P., \& Santos, A. C. dos. (2019). The brand new Brazilian specialty coffee market. Journal of Food Products Marketing, 25(1), 49-71.

Gutman, J. (1982). A means-end chain model based on consumer categorization processes. Journal of marketing, 46(2), 60-72.

Ha, J., \& Jang, S. C. (2013). Attributes, consequences, and consumer values: A means-end chain approach across restaurant segments. International Journal of Contemporary Hospitality Management, 25, 383-409.

Ikeda, A. A., Campomar, M. C., \& Chamie, B. C. (2014). Laddering: revelando a coleta e interpretação dos dados. Revista Brasileira de Marketing, 13(4), 49-66.

Janghorban, R., Roudsari, R. L., \& Taghipour, A. (2014). Skype interviewing: The new generation of online synchronous interview in qualitative research. International Journal of Qualitative Studies on Health and Well-being, 9(1), 24152.

Kahle, L. R., Poulos, B., \& Sukhdial, A. (1988). Changes in social values in the United States during the past decade. Journal of Advertising Research, 28, 35-41.

Krishna, A. (2012). An integrative review of sensory marketing: Engaging the senses to affect perception, judgment and behavior. Journal of Consumer Psychology, 22(3), 332-351.

Lang, M. \& Lemmerer, A. (2018). How and why restaurant patrons value locally sourced foods and ingredients. International Journal of Hospitality Management, 77, 76-88.

Lee, J., Sneddon, J., Daly, T., Schwartz, S., Soutar, G., \& Louviere, J. (2019). Testing and extending Schwartz refined value theory using a best-worst scaling approach. Assessment, 26(2), 166-180.

Maxim, R., Magun, V., \& Schwartz, S. (2018). Relations among higher order values around the world. Journal of Cross-Cultural Psychology, 49(8), 1165-1182.

Maximino, R. C. (2018). Limiares sensoriais para concentração de café conilon (Coffea canephora) no café arábica (Coffea arabica), perfil sensorial pela análise tempo - intensidade e percepção dos consumidores em relação à bebida. Dissertação de mestrado em Ciência e Tecnologia de Alimentos, Universidade Federal do Espírito Santo, Alegre, ES, Brasil.

Mello, V., G., Franco, J. O. B., \& Pépece, O. M. C. (2020). Abandono de Consumo: Mudanças nos significados de consumo de café na onda dos cafés especiais. Consumer Behavior Review, 4(3), 245-260. 
Oliveira, T. M. V. de., \& Ikeda, A. A. (2004). Usos e limitações do método laddering. RAM. Revista de Administração Mackenzie, 5(1), 198-222.

Pimenta, M. L., Piato, E.L., Vilas Boas, L. H. De B., \& Moriguchi, S. N. (2012). Flavor and wellbeing: relationship between product's attributes and consumers personal values of regional coffee brands. Brazilian Business Review, 9(3), 119-140.

Rokeach, M. (1973). The nature of human values. Free: New York.

Rokeach, M. (1989). Stability and Change in American Value Priorities, 1968-1981. American Psychologist, 44(5), 775-784.

Reynolds, T. J., \& Gutman, J. (1988). Laddering theory, method, analysis, and interpretation. Journal of Advertising Research, 28(1), 11-31.

Samoggia, A., \& Riedel, B. (2018). Coffee consumption and purchasing behavior review: Insights for further research. Appetite, 129, 70-81.

Schwartz S. H. (1992). Universals in the content and structure of values: Theory and empirical tests in 20 countries. Adcances in Experimentel Social Ppsychology, 25(1), 25-65.

Schwartz, S. H. (2017). The refined theory of basic values. Values and Behavior, pp. 51-72.

Schwartz, S. H., \& Butenko, T. (2014). Values and behavior: validating the refined value theory in Russia. European Journal of Social Psychology, 44(7), 799-813.

Schwartz, S. H., Cieciuch, J., Vecchione, M., Davidov, E., Fischer, R., Beierlein, C., Ramos, A., Verkasalo, M., Lonnqvist, J. E., Demirutku, K., Dirilen-Gumus, O., \& Konty, M. (2012). Refining the theory of basic individual values. Journal of Personality and Social Psychology, 103(4), 663-668.

Silva, M. S. M. da. (2017). $O$ valor-gradiente em marcas de café - midiatização da cultura e do desejo a partir de Nespresso e Starbucks. Tese de doutorado em Estudo dos Meios e da Produção Mediática, Universidade de São Paulo, São Paulo, SP, Brasil.

Solomon, M. R. (2016). O Comportamento do consumidor: comprando, possuindo e sendo. (11a ed.). Porto Alegre: Bookman Editora.

Sresnewsky, K. B. G. B., Veloso, A. R., Ikeda, A. A., \& Rocha, R. R. (2018). The use of Photo-elicitation in marketing research. Revista Brasileira de Marketing, 17(6), 839-848.

Vilas Boas, L. H. de B. (2005). Comportamento do consumidor de produtos orgânicos - uma análise na perspectiva da Teoria da Cadeia de Meios e Fins. Tese de doutorado em Administração, Universidade Federal de Lavras, Lavras, MG, Brasil.

Vilas Boas, L. H. de B., Sette, R. de Souza, \& Brito, M. J. de. (2006). Comportamento do consumidor de produtos orgânicos: uma aplicação da teoria da cadeia de meios e fins. Organizações Rurais \& Agroindustriais, 8(1), 25-39.

Vinuto, J. (2014). A amostragem em bola de neve na pesquisa qualitativa: um debate em aberto. Temáticas, 22(44), 203-220.

Walker, B. A., \& Olson, J. C. (1991). Means-end chains: Connecting products with self. Journal of Business Research, 22(2), 111-118. 
APÊNDICE

Tabela 2 - Matriz de Implicação dos consumidores de café em cápsula

\begin{tabular}{|c|c|c|c|c|c|c|c|c|c|c|c|c|c|c|c|c|c|c|c|c|c|c|c|c|c|c|c|c|c|c|c|c|}
\hline CÓDIGOS & 2 & 4 & & 7 & 89 & 9 & 101 & 111 & \begin{tabular}{l|l|}
12 & 13
\end{tabular} & 14 & \begin{tabular}{|l|l|}
15 & 16 \\
\end{tabular} & 17 & 18 & 192 & \begin{tabular}{|l|l|}
20 & 21
\end{tabular} & \begin{tabular}{l|l|}
21 & 22 \\
\end{tabular} & 23 & 24 & 25 & 26 & 27 & \begin{tabular}{|l|l|}
28 & 2
\end{tabular} & \begin{tabular}{|l|l|}
229 & 31
\end{tabular} & 30 & 31 & 32 & 33 & 34 & 35 & Soma Sd. & $\mid \begin{array}{c}\text { Soma: Ent. } \\
+ \text { Sd. }\end{array}$ & Centralidade \\
\hline 1- Monodoses & 110 & & & $0 \mid 1$ & & 0123 & 30 & & & $0 \mid 1$ & $4 \mid 1$ & $0 \mid 2$ & $0 \mid 1$ & $0 \mid 1$ & & & & 015 & & & $0 \mid 1$ & $0 \mid 1$ & & & $0 \mid 2$ & & & & $0 \mid 2$ & $8 \mid 20$ & $8 \mid 20$ & 0,016 \\
\hline 2- Não sustentável & & & & & & & & & & & $3 \mid 0$ & & & & & & & & & & $1 / 2$ & & & & & & & & & $4 \mid 2$ & $5 / 2$ & 0,01 \\
\hline 3- Variedade & & 200 & & $8 / 2$ & & & \begin{tabular}{l|l}
$\mid 1$ & 1 \\
1
\end{tabular} & 100 & 04 & 016 & & $0 \mid 2$ & $0 \mid 2$ & $0 \mid 1$ & & $0 \mid 1$ & $0 \mid 2$ & 013 & & 014 & & & & & $0|1|$ & $0|1| c$ & $0 \mid 1$ & $0 \mid 2$ & $0 \mid 1$ & 1234 & 1234 & 0,024 \\
\hline \begin{tabular}{|l|} 
4- Origem \\
\end{tabular} & & & & 100 & & & & & & $1 \mid 1$ & & & & & & & & & & $0 \mid 1$ & & & & & & & & $0 \mid 1$ & & $2 / 3$ & $4 / 3$ & 0,008 \\
\hline 5- Características da bebida & & & & 310 & & & 100 & & & $1 \mid 0$ & & $0 \mid 1$ & $0 \mid 1$ & $0 \mid 2$ & & $0 \mid 1$ & $0 \mid 1$ & $0 \mid 1$ & & $0 \mid 1$ & & $0 \mid 1$ & & & $0|1|$ & $0|1| c$ & $0 \mid 2$ & & & $5 \mid 12$ & $5 \mid 12$ & 0,01 \\
\hline 6-Preço Alto & & & & 100 & & 10 & 100 & & & & 1100 & $0 \mid 1$ & $0 \mid 1$ & & $0|1| 0 \mid 1$ & \begin{tabular}{|l|l|}
1 & $0 \mid 1$ \\
\end{tabular} & $0 \mid 1$ & & & & $0 \mid 1$ & & $0 \mid 1$ & & $0 \mid 1$ & & & $0 \mid 1$ & & $4 \mid 10$ & $4 \mid 10$ & 0,008 \\
\hline 7-Sabor & & & & & $2|0| 1 \mid$ & & \begin{tabular}{l|l}
$3 \mid 0$ & 1 \\
\end{tabular} & 100 & 711 & 613 & $1 \mid 1$ & $1 \mid 1$ & $0 \mid 3$ & 115 & 100 & $3 / 3$ & 016 & 119 & 110 & 114 & $0 \mid 2$ & \begin{tabular}{|l|l|}
$0 \mid 6$ & 0 \\
\end{tabular} & $0|1| 0 \mid$ & $0 \mid 1$ & $0|6| 6$ & $0 \mid 20$ & 012 & 013 & $0 \mid 6$ & $30 \mid 66$ & 4369 & 0,087 \\
\hline 8- Pior qualidade & & & & & & & & & & & $3 \mid 1$ & & & & & $0 \mid 1$ & & & & & 0,4 & & & & & & & & & 316 & 516 & 0,01 \\
\hline 9- Exchisivo e luxuoso & & & & & & & $1 \mid 1$ & & & 110 & 110 & $0 \mid 1$ & $0 \mid 1$ & 00112 & $2 \mid 1$ & & & $0 \mid 1$ & & 10 & & $0 \mid 1$ & 013 & & & & & $0 \mid 2$ & $0 \mid 1$ & $5 \mid 14$ & 7717 & 0,014 \\
\hline 10- Praticidade e conveniência & & & & & & & & & 110 & $0 \mid 1$ & $0 \mid 1$ & $18 / 2$ & $0 \mid 15$ & 0170 & $|0| 1|0| 1$ & \begin{tabular}{|l|l|}
$\mid 1$ & $0 \mid 2$ \\
\end{tabular} & $0 \mid 7$ & 116 & & $0 \mid 3$ & & 013 & $0 \mid 1$ & & 018 & $0 \mid 2$ & & 015 & 015 & 20170 & $30 \mid 72$ & 0,061 \\
\hline \begin{tabular}{|l|}
$11-$ Aroma \\
\end{tabular} & & & & & & & & & $0 \mid 1$ & 100 & & & & $1 \mid 1$ & & $0 \mid 2$ & & 200 & & $0 \mid 1$ & & & & & 0,200 & $0 \mid 1$ & $0 \mid 1$ & & $0 \mid 2$ & $4 \mid 11$ & $6 \mid 11$ & 0,012 \\
\hline 12- Preço baixo & & & & & & & & & & & 10 & & & & & & & $0 \mid 1$ & & & & $0 \mid 1$ & & & & & & & & $1 / 2$ & 22 & 0,004 \\
\hline 13- Melhora o paladar & & & & & & & & & & 30 & & & & $0 \mid 1$ & & $0 \mid 2$ & $0 \mid 2$ & $3 \mid 1$ & & 110 & & & & & $0 \mid 2$ & $0 \mid 1$ & 10 & & $0 \mid 1$ & $8 \mid 10$ & $15 \mid 16$ & 0,03 \\
\hline 14- Aumenta a experiềncia o o consumo & & & & & & & & & & & & & 100 & $2 \mid 1$ & & $0 \mid 1$ & & $3 \mid 1$ & & 212 & & $0 \mid 1$ & & & $0 \mid 1$ & $0 \mid 3$ & $0 \mid 1$ & $0 \mid 2$ & $0 \mid 2$ & $8 \mid 14$ & 2126 & 0,043 \\
\hline 15- Diminuição do consumo & & & & & & & & & & & & & & & 110 & \begin{tabular}{l|l|}
10 & 110 \\
\end{tabular} & & & & & $5 / 2$ & & & & & & & & & $7 / 2$ & $15 \sqrt{4}$ & 0,03 \\
\hline 16- Poupa recursos & & & & & & & & & & & & 10 & & & & & & $3 \mid 1$ & & & & $0 \mid 1$ & & & $1 \mid 1$ & & & & $0 \mid 1$ & $5 / 4$ & 1116 & 0,022 \\
\hline \begin{tabular}{|l} 
17- Otimiza tarefas \\
\end{tabular} & & & & & & & & & & & & & $13 \mid 1$ & 0161 & \begin{tabular}{|l|l|l}
10 & 110 \\
\end{tabular} & \begin{tabular}{|l|l|}
10 & $0 \mid 2$ \\
\end{tabular} & 25 & 24 & & $1 / 2$ & & \begin{tabular}{|c|c|c|}
$0 \mid 2$ & 1 \\
\end{tabular} & $0 \mid 1$ & & 018 & $0 \mid 2$ & & 015 & 0,4 & 2042 & 40152 & 0,081 \\
\hline 18- Otimiza tempo & & & & & & & & & & & & & & 40 & & $1 \mid 1$ & $4 \mid 1$ & $3 \mid 1$ & & 300 & & $0 \mid 1$ & & & 015 & $0 \mid 2$ & & $0 \mid 3$ & 0,4 & $15 \mid 18$ & 2943 & 0,059 \\
\hline 19- Sinto-me tranquilo e bem humorado & & & & & & & & & & & & & & & \begin{tabular}{|l|l|}
10 & 110 \\
\end{tabular} & \begin{tabular}{l|l|}
10 & 50 \\
\end{tabular} & $22^{2}$ & 310 & & $0 \mid 1$ & & $0|2|$ & 1100 & $0 \mid 1$ & 315 & $0 \mid 1$ & 110 & $0 \mid 2$ & 114 & $18 \mid 18$ & 26144 & 0,053 \\
\hline 20- Cria differenciação & & & & & & & & & & & & & & & & & & & & 110 & & & $3 \mid 1$ & & $\square$ & & & 013 & & $4 \mid 4$ & 818 & 0,016 \\
\hline 21- Sinto mal-estare de mal humorado & & & & & & & & & & & & & & & & & & & & & 10 & & & & $0 \mid 1$ & & & & $0 \mid 1$ & $1 / 2$ & 44 & 0,008 \\
\hline 22- Sento-me motivado & & & & & & & & & & & & & & & & & $3 \mid 1$ & $2 \mid 2$ & & 110 & 110 & $2 \mid 1$ & & & 25 & $0 \mid 1$ & & & 115 & $12 \mid 15$ & $22 \mid 32$ & 0,045 \\
\hline 23- Sentir-se produtivo e concentrado & & & & & & & & & & & & & & & & & & 312 & & $0 \mid 1$ & & 210 & & $0 \mid 1$ & $6 / 4$ & 100 & & $0 \mid 3$ & $\frac{12}{12}$ & $13 \mid 13$ & 2440 & 0,049 \\
\hline 24- Sinto-me satisfeito e de bem-estar & & & & & & & & & & & & & & & & & & & & 200 & & $4 \mid 1$ & & $0 \mid 1$ & 315 & $0 \mid 1$ & & $0 \mid 1$ & 24 & 11113 & 3749 & 0,075 \\
\hline 25- Não prejudicar a saúde & & & & & & & & & & & & & & & & & & & & & & & & & & & & & & 0 & $1 \mid 1$ & 0,002 \\
\hline 26- Permitii & & & & & & & & & & & & & & & & & & & & & & $0 \mid 1$ & $0 \mid 1$ & & & 411 & 110 & $2 \mid 1$ & $0 \mid 1$ & 715 & $20 \mid 25$ & 0,041 \\
\hline 27- Chateacẫo e tristeza & & & & & & & & & & & & & & & & & & & & & & & & & & & & & & 0 & $8 \mid 12$ & 0,016 \\
\hline 28- Hedonismo & & & & & & & & & & & & & & & & & & & & & & & & 10 & $2 \mid 1$ & & & & $0 \mid 2$ & $3 / 3$ & 11126 & 0,022 \\
\hline 29- Prestígio & & & & & & & & & & & & & & & & & & & & & & & & & & & & 310 & & 30 & 799 & 0,014 \\
\hline 30- Autodirecão - pensamento & & & & & & & & & & & & & & & & & & & & & & & & & 100 & & & & & 10 & 24 & 0,004 \\
\hline 31- Autodireção - ação & & & & & & & & & & & & & & & & & & & & & & & & & & & & 20 & 70 & 910 & 2759 & 0,055 \\
\hline 32- Benevolência - carinho & & & & & & & & & & & & & & & & & & & & & & & & & & & 110 & 20 & & $3 \mid 0$ & 8119 & 0,016 \\
\hline 33- Estimulação & & & & & & & & & & & & & & & & & & & & & & & & & & & & & & 0 & $4 \sqrt{4}$ & 0,008 \\
\hline 34- Segurança - pessoal & & & & & & & & & & & & & & & & & & & & & & & & & & & & & & 0 & $9 / 34$ & 0,018 \\
\hline 35- Realização & & & & & & & & & & & & & & & & & & & & & & & & & & & & & & 0 & $\frac{304}{1248}$ & $\begin{array}{l}0,010 \\
0.024\end{array}$ \\
\hline Soma Ent. & $|10|$ & 20 & & $13 \mid 3$ & 2012 & $2 \sqrt[3]{1}$ & $10 \mid 2$ & 200 & \begin{tabular}{l|l}
10 & 76 \\
\end{tabular} & $13 \mid 12$ & $8|26| 2$ & $20 \mid 10$ & $14 \mid 25$ & 81265 & $5|33| 3 \mid 2$ & \begin{tabular}{l|l|l|}
$3 \mid 2$ & $10 \mid 17$ \\
\end{tabular} & 11127 & $26|36| 1$ & $|1| 1$ & $13 \mid 20$ & $8 \mid 128$ & 823 & $4|9| 1$ & & 1859 & $5 \mid 19$ & 477 & 09934 & 12448 & 2466413 & 4921826 & 1 \\
\hline
\end{tabular}

Fonte: Dos autores (2020) - auxílio do Software LadderUX. 